\title{
Occurrence of Pink Mold Rot of Strawberry Caused by Trichothecium roseum in Korea
}

\author{
Jin-Hyeuk Kwon ${ }^{1 *}$, Shun-Shan Shen ${ }^{2}$ and Jinwoo Kim ${ }^{3}$ \\ ${ }^{1}$ Gyeongsangnam-do Agricultural Research and Extension Services, Jinju 660-360, Korea \\ ${ }^{2}$ College of Plant Protection, Henan Agricultural University, Zhengzhou 450002, China \\ ${ }^{3}$ Institute of Agriculture and Life Science and Department of Applied Biology, Gyeongsang National University, Jinju 660-701, \\ Korea
}

(Received on July 15, 2010; Accepted on August 4, 2010)

Strawberries rotted by pink mold rot fungus (Trichothecium roseum) were found sporadically in farm greenhouses in Sugokmyon, Jinju, Korea, from March to April in 2009 and 2010. The diseased fruits were first covered with pink-colored mold, consisting of conidia and conidiophores of the pathogen, and then became water-soaked and dark brown in color, before eventually rotting(Fig. 1A). After a pure representative specimen was isolated, we examined the mycological characteristics of the specimens in detail, using light and scanning electron microscopes. Fungal colonies were white to pinkish, and numerous conidia formed on potato dextrose agar (PDA; Fig. 1C). Conidia were ellipsoidal to pyriform, colorless, 2-celled, characteristically held together in zigzag chains, aleurioconidia $12-21 \times 8-10 \mu \mathrm{m}$ in size (Fig. 1D). Conidiophores were long, slender, simple, septate, bearing meristem arthrospore conidia apically, singly when young, and successively. Conidiophores were apex, 3-5 $\mu \mathrm{m}$ in size. The optimum temperature for mycelial growth was $25^{\circ} \mathrm{C}$. The measurements and taxonomic characteristics coincided with those of $T$. roseum (Pers.) Link ex Gray described by Gobayashi et al. (1992) and Ishikawa et al. (1998). The pure isolate of the pathogen was incubated at $25^{\circ} \mathrm{C}$, and the conidia were artificially inoculated onto strawberries. The same disease symptoms were reproduced on the fruits, and the same fungus was re-isolated from the symptoms.

To identify the causal fungus, we amplified and sequenced a partial internal transcribed space (ITS) rDNA of the isolate, using the primers ITS 1 and ITS4, as described by White et al. (1990). The resulting sequence of $613 \mathrm{bp}$ was deposited in GenBank (accession no. HM355750). Phylogenetic analysis was conduced using MEGA4 software, with the neighbor-joining method and Tajima-

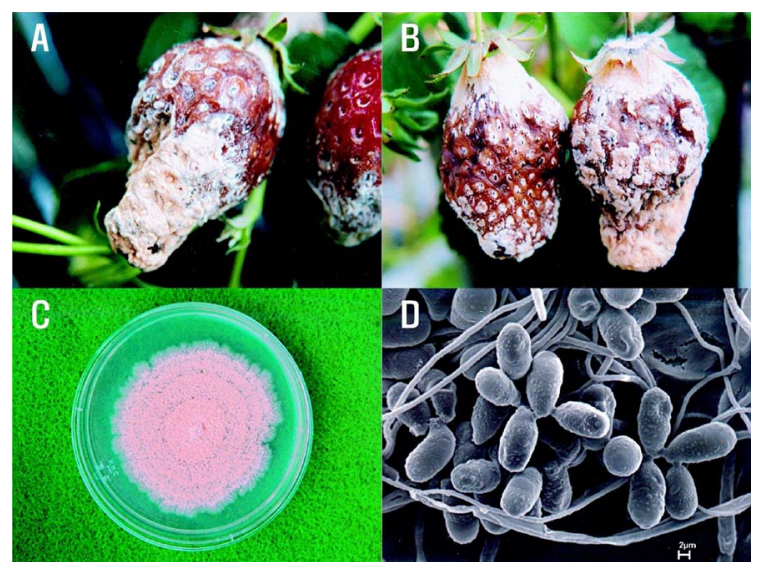

Fig. 1. Pink mold rot on strawberry fruits caused by Trichothecium roseum. A: Naturally infected fruits; B: Symptoms induced by artificial inoculation; C: Mycelial colony grown for 10 days on PDA; D: Scanning electron microscope images of conidia and conidiophores of $T$. roseum.
Nei distance model. The neighbor-joining analysis (Fig. 2) showed that the ITS sequences of the isolate were similar to those of $T$. roseum (Seifert et al., 1997). In the phylogenetic tree (Fig. 2), the isolate was placed within a clade comprising reference isolates of $T$. roseum. This is the first report of pink mold rot on strawberry caused by $T$. roseum in Korea. Cultures of T. roseum have been deposited with the Korean Agricultural Culture Collection (KACC 45158), National Institute of Agricultural Biotechnology, RuralDevelopment Administration, Suwon.

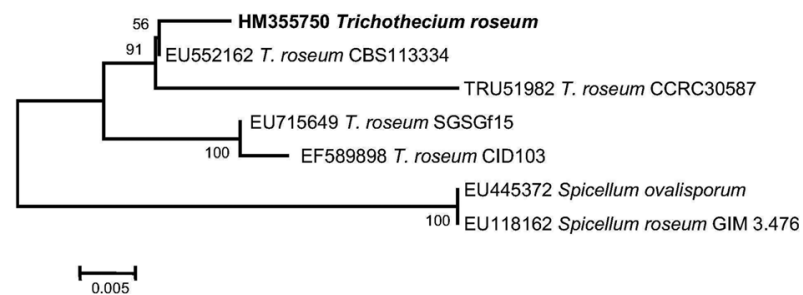

Fig. 2. Phylogenetic tree based on ITS sequences, showing closest known relatives of Trichothecium roseum, including the pink mold rot fungus infecting strawberries. DNA sequences from the US National Center for Biotechnology Information (NCBI) nucleotide database were aligned using ClustalX, and a phylogenetic tree was constructed using the neighborjoining method and visualized with TreeView. Numbers above the branches indicate bootstrap values. Bars indicate number of nucleotide substitutions per site. The isolate infecting strawberries is indicated in bold.

\section{Acknowledgment}

This work was carried out with the support of Cooperative Research Program for Agriculture Science \& Technology Development (Project No. PJ007345), Rural Development Administration, Republic of Korea.

\section{References}

Gobayashi, T., Katumoto, K., Abiko, K., Abe, Y. and Kakishima, M. 1992. Illustrated genera of plant pathogenic fungi in Japan. The Whole Farming Educational Association. 534 pp.

Ishikawa, S., Miya, M., Ohno, Y. and Goto, T. 1998. First report of pink mold rot of strawberry caused by Trichothecium roseum in the system of raised nursery plants in the air. Ann. Phytopathol. Soc. Jpn. 64:431.

Seifert, K., Louis-Seize, G.. and Savard, M. E. 1997. The phylogenetic relationships of two trichothecene-producing hyphomycetes, Spicellum roseum and Trichothecium roseum. Mycologia 89:250-257.

White, T. J., Bruns, T., Lee, S. and Taylor, J. W. 1990. Amplification and direct sequencing of fungal ribosomal RNA genes for phylogenetics. In: PCR Protocols: A Guide to Methods and Applications, ed. by M.A. Innis, D.H. Gelfand, J.J. Sninsky, and T.J. White. pp. 315-322. Academic Press, Inc., New York

*Corresponding author (kwon825@korea.kr) 